\title{
Avaliação do efeito genotóxico do Prozac (fluoxetina), sem e com adição de vitaminas A e $C$, através do teste do cometa em cultura de células CHO-K1
}

\author{
Evaluation of genotoxic effect of prozac (fluoxetine) without and with \\ addition of vitamins $A$ and $C$ by means of the comet assay in culture of \\ CHO-K1 cells
}

\author{
Noélle Giacomini Lemos ${ }^{1}$; Mário Sérgio Mantovanii ${ }^{1}$; Veronica E. P. Vicentini²
}

\section{Resumo}

A fluoxetina, com nome comercial Prozac, é eficaz contra a depressão maior e a ansiedade com menor risco de causar efeitos colaterais. Contudo, os possíveis efeitos genotóxicos ainda são desconhecidos. A utilização de vitaminas como protetoras de danos nas células e no DNA têm sido avaliada, principalmente para as vitaminas A e C, e além disso o efeito associativo das vitaminas com diversos medicamentos necessita de mais estudos. As avaliações do efeito genotóxico do prozac e do efeito protetor das vitaminas A e C foram realizadas em cultura de células de ovário de hamster chinês da linhagem CHO-K1, através do teste do cometa. Foi utilizado o prozac em formulação líquida diluído em concentrações de $5 \mathrm{mg}, 1 \mathrm{mg}$ e $0,2 \mathrm{mg} / \mathrm{mL}$ de meio de cultura. As vitaminas A e C, respectivamente, foram utilizadas na formulação líquida nas concentrações de $3 \mathrm{mg}$ e $880,5 \mathrm{mg} / \mathrm{mL}$ de meio de cultura. Os tratamentos foram feitos durante $1 \mathrm{~h}$. Os dados obtidos demonstraram que somente a concentração mais alta de prozac (5mg) foi genotóxica e tanto a vitamina A quanto a $\mathrm{C}$ reduziram essa genotoxicidade. Assim, sugerimos um monitoramento em pacientes que fazem uso do prozac e a possibilidade de associação das vitaminas A e C para minimizar os efeitos genotóxicos colaterais.

Palavras-chave: Fluoxetina. Ensaio do Cometa. Vitaminas A e C. CHO-k1.

\begin{abstract}
The fluoxetine, commercially named Prozac, is efficient against depression and anxiety, with lower risk of collateral effects. However, the possible genotoxic effects are still unknown. The use of vitamins as protectors against damages on cells and DNA has been evaluated, mainly for vitamins A and C. Furthermore, the associative effect of vitamins with several medicines demands studies. The evaluations of genotoxic effect of Prozac and vitamins A and C protective effect were carried out in culture of Chinese hamster ovary cells, CHO-K1, by means of the comet test. The Prozac was used, in liquid formulation, diluted in $5 \mu \mathrm{g}, 1 \mu \mathrm{g}$ and $0.2 \mu \mathrm{g} / \mathrm{mL}$ of culture medium. The vitamins were used, in liquid formulation, at the concentrations of $3 \mu \mathrm{g}$ and $880,5 \mu \mathrm{g} / \mathrm{mL}$ of culture medium to vitamins $\mathrm{A}$ and $\mathrm{C}$, respectively. The treatments were carried out during 1 hour. The obtained data demonstrated that only the highest concentration of Prozac $(5 \mu \mathrm{g})$ is genotoxic and both vitamins $\mathrm{A}$ and $\mathrm{C}$ reduced such genotoxicity. The data suggest a follow-up on patients who use Prozac and the possibility of vitamins A and $\mathrm{C}$ association in order to minimize the collateral genotoxic effects.

Key words: Fluoxetine. Vitamins A and C. CHO-k1. Comet assay.
\end{abstract}

1 Universidade Estadual de Londrina - Londrina, Paraná.

2 Universidade Estadual de Maringá - Maringá, Paraná 


\section{Introdução}

O Prozac, nome comercial do cloridrato de fluoxetina, é o primeiro representante da chamada nova geração de antidepressivos, drogas que garantem eficácia no tratamento da depressão maior e ansiedade com menor risco de causar efeitos colaterais (WOOD, 1994). Apesar de ser muito utilizado, seus possíveis efeitos genotóxicos ainda são desconhecidos. Esses efeitos podem ser a causa primária de danos cromossômicos nas células, ou seja, podem estar relacionados ao surgimento de neoplasias.

A vitamina A é um protetor natural muito importante com propriedades antioxidante e antimutagênica, e a vitamina $C$, quando deficiente no organismo, pode produzir níveis significantes de danos genéticos, mas ainda são necessários muitos estudos para compreender o modo de atividade dessas duas vitaminas (ODIN, 1997). Sabe-se, atualmente, que as vitaminas A e C estão sendo amplamente utilizadas como antimutagênicos. Contudo, o efeito no genoma da célula, quando associamos vitaminas com medicamentos, necessita ser melhor avaliado.

Dentre os testes de triagem feitos para se detectar efeitos genotóxicos de fármacos, aplicados antes destes serem colocados no mercado, cita-se o teste do cometa (SINGH et al., 1988). O parâmetro de análise que o teste fornece é a quebra de fita simples de DNA, e os segmentos gerados migram do núcleo, de acordo com o dano ocorrido na molécula. O uso desse teste tem sido proposto devido sua alta sensibilidade quando comparado com outros testes de genotoxicidade. Neste trabalho, avaliamos a atividade genotóxica do Prozac (Fluoxetina), bem como do potencial antigenotóxico das vitaminas A e C em associação ao Prozac, por meio da técnica de indução de quebra de fita simples (Ensaio do Cometa), em cultura de células de mamíferos da linhagem CHO-K1.

\section{Materiais e Métodos}

\section{Agentes químicos}

Para o controle positivo, utilizou-se o metilmetano sulfonato (MMS) (Aldrich) (120mM). O Prozac (5mg, $1 \mathrm{mg}$ e $0,2 \mathrm{mg} / \mathrm{mL}$ de meio de cultura) foi utilizado na formulação líquida. As vitaminas A (3mg/ $\mathrm{mL}$ de meio de cultura) e $\mathrm{C}(880,5 \mathrm{mg} / \mathrm{mL}$ de meio de cultura) foram utilizadas em formulação líquida (HOCHE). Todas as concentrações foram definidas em experimentos piloto.

\section{Cultura de células}

O teste foi realizado em cultura de células de ovário de hamster chinês (CHO-K1), com ciclo de divisão de aproximadamente $14 \mathrm{~h}$, crescidas em meio de cultura HAM-F10:D-MEM (1:1), suplementado com $10 \%$ de soro bovino fetal, mantido em estufa a $37^{\circ} \mathrm{C}$.

\section{Ensaio do Cometa e Protocolos Experimentais}

As células foram cultivadas por 24 horas quando receberam os tratamentos por $1 \mathrm{~h}$, e logo após a colheita sofreram tripsinização rápida. Treze tratamentos foram feitos, e eles consistiram em um controle negativo, um controle positivo com MMS $(120 \mathrm{mM})$, três concentrações decrescentes de Prozac (5mg, $1 \mathrm{mg}$ e $0,2 \mathrm{mg} / \mathrm{mL}$ de meio de cultura), duas culturas somente com as vitaminas $\mathrm{A}(3 \mathrm{mg} / \mathrm{mL}$ de meio de cultura) e $\mathrm{C}(880,5 \mathrm{mg} / \mathrm{mL}$ de meio de cultura) e as restantes com as vitaminas associadas às diferentes concentrações do Prozac. Foram feitas três repetições independentes.

Após a colheita, a suspensão celular $(20 \mathrm{~mL})$ de cada cultura foi homogeneizada com $120 \mathrm{~mL}$ de $0,5 \%$ de agarose de baixo ponto de fusão (LMP) e aplicada em lâminas pré-gelificadas com 1,5\% de agarose normal. Em seguida, foram cobertas por lamínulas e deixadas dez minutos na geladeira. Logo após, foram retiradas as lamínulas e as lâminas colocadas em uma solução de lise $(1 \mathrm{~mL}$ Triton-X $+10 \mathrm{~mL}$ DMSO + 89 
mL de solução estoque: $2,5 \mathrm{M} \mathrm{NaCl}$; $100 \mathrm{mM}$ EDTA; 10mM Tris; $8 \mathrm{~g} \mathrm{NaOH} ; 1 \%$ Na lauryl sarcosinato; pH 10), e deixadas no mínimo 1 h para que se destituíssem os componentes de membrana das células. Após a lise, as lâminas foram colocadas em uma cuba de eletroforese e cobertas com um tampão alcalino $(30 \mathrm{~mL} \mathrm{NaOH} 10 \mathrm{~N}+5 \mathrm{~mL}$ EDTA $200 \mathrm{mM}$, $\left.\mathrm{pH} 10+965 \mathrm{~mL} \mathrm{H}_{2} \mathrm{O}\right)$. Estas foram deixadas em descanso por 20 min para denaturação do DNA, e mais 20 min em corrida a $25 \mathrm{~V}$ e $300 \mathrm{~mA}$. Em seguida, as lâminas foram neutralizadas em solução Tris $0,4 \mathrm{M}$ $\mathrm{pH} 7,5$ por $15 \mathrm{~min}$ e por último deixadas no fixador (etanol) por 10min. A análise foi feita em microscópio de fluorescência filtro B- ${ }^{\mathrm{A}}$ e o corante utilizado foi o Brometo de Etídio.

\section{Análise das lâminas e Estatística}

O padrão de análise de acordo com a quantidade de fita simples que migrava do núcleo (classificação visual), dava-nos as seguintes classes: a) classe zero, a não evidência de dano celular (não ocorre migração); b) classe um, dano pequeno (migração de fragmentos à distâncias de um diâmetro do núcleo); b) classe dois, dano médio (migração de dois diâmetros do núcleo); d) classe três, dano alto (migração de mais de dois diâmetros do núcleo) (Figura 1). Com a obtenção das classes em 100 núcleos analisados/experimento, calculamos o valor de escore através da somatória do número de núcleos encontrados em cada classe vezes o valor da sua respectiva classe. A análise estatística foi realizada com o teste do $\mathrm{c}^{2}$ com $\mathrm{a}=0,05$.

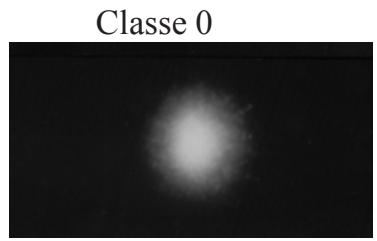

Classe 2

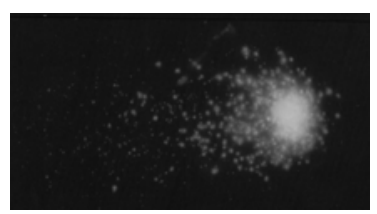

Figura 1: Distribuição dos tipos de cometas classificados como $0,1,2$ e 3 (sem danos visíveis)

\section{Resultados e Discussão}

$\mathrm{Na}$ Tabela 1, verificou-se que das três concentrações de Prozac avaliadas, somente a maior apresentou atividade genotóxica $(5 \mathrm{mg} / \mathrm{mL})$. As vitaminas nas concentrações testadas não foram genotóxicas e, quando associavam-se a vitamina $\mathrm{A}$ e a vitamina $\mathrm{C}$ com a maior concentração de Prozac, observou-se que houve uma redução na genotoxicidade desse medicamento. Com isso, pôdese avaliar o efeito antigenotóxico das vitaminas somente associadas à concentração genotóxica, mais elevada, de prozac $(5 \mathrm{mg} / \mathrm{mL})$. Esses dados sugerem que tanto a vitamina A quanto a $\mathrm{C}$ podem reduzir os danos primários no DNA causados pelo prozac, em concentrações elevadas. 
Lemos, N. G.; Mantovani, M. S.; Vicentini, V. E. P.

Tabela 1. Análise das classes de cometa obtidas em cada tratamento com Prozac, vitamina A e C, em cultura de células CHO-K1.

\begin{tabular}{cccccccc}
\hline \multicolumn{2}{c}{ Tratamentos } & \multicolumn{2}{c}{ Número de células } & \multicolumn{2}{c}{ Classes (\%) } & \multicolumn{2}{c}{ Escore } \\
\hline & Analisadas & $\begin{array}{c}\text { Com danos } \\
(\%)\end{array}$ & 0 & 1 & 2 & 3 & \\
\hline$C^{-}$ & 300 & 0 & 100 & 0 & 0 & 0 & 0 \\
$\mathrm{C}^{+}$ & 300 & $100^{*}$ & 0 & 23 & 39 & 38 & 215 \\
$\mathrm{P} 1$ & 300 & $19^{*}$ & 81 & 0 & 19 & 0 & 38 \\
$\mathrm{P} 2$ & 300 & 0 & 100 & 0 & 0 & 0 & 0 \\
$\mathrm{P} 3$ & 300 & 0 & 100 & 0 & 0 & 0 & 0 \\
$\mathrm{VA}$ & 300 & 0 & 100 & 0 & 0 & 0 & 0 \\
$\mathrm{VA}+\mathrm{P} 1$ & 300 & $0 * *$ & 100 & 0 & 0 & 0 & 0 \\
$\mathrm{VA}+\mathrm{P} 2$ & 300 & 0 & 100 & 0 & 0 & 0 & 0 \\
$\mathrm{VA}+\mathrm{P} 3$ & 300 & 0 & 100 & 0 & 0 & 0 & 0 \\
$\mathrm{VC}$ & 300 & 0 & 100 & 0 & 0 & 0 & 0 \\
$\mathrm{VC}+\mathrm{P} 1$ & 300 & $0 * *$ & 100 & 0 & 0 & 0 & 0 \\
$\mathrm{VC}+\mathrm{P} 2$ & 300 & 0 & 100 & 0 & 0 & 0 & 0 \\
$\mathrm{VC}+\mathrm{P} 3$ & 300 & 0 & 100 & 0 & 0 & 0 & 0 \\
\hline
\end{tabular}

$\mathrm{C}^{-}=$controle negativo; $\mathrm{C}^{+}=$controle positivo $(120 \mathrm{mM}$ de MMS); $\mathrm{P} 1=5 \mathrm{mg}$ de prozac $/ \mathrm{mL} ; \mathrm{P} 2=1 \mathrm{mg}$ de prozac $/ \mathrm{mL} ; \mathrm{P} 3$ $=0,2 \mathrm{mg}$ de prozac $/ \mathrm{mL} ; \mathrm{VA}=3 \mathrm{mg}$ de vitamina $\mathrm{A} / \mathrm{mL} ; \mathrm{VC}=880,5 \mathrm{mg}$ de vitamina $\mathrm{C} / \mathrm{mL} ; *$ diferença estatística significativa quando comparado ao controle negativo; ** diferença estatística significativa quando comparado ao tratamento P1.

Alguns efeitos biológicos do Prozac têm sido avaliados, principalmente quanto a sua toxicidade. No trabalho feito por Sacerdote, Biachi e Panerai (1994), foi observado que a fluoxetina (princípio ativo do prozac) não afetava a mobilidade de células polimorfonucleadas humanas in vitro. A avaliação dos efeitos da exposição pré-natal da fluoxetina na neurotoxicidade do desenvolvimento em ratos mostrou que esta não foi neurotóxica (Vorhees et al., 1994). Byrd e Markham (1994) verificaram que a fluoxetina não exibiu qualquer toxicidade para o desenvolvimento dos conceptos de ratos e coelhos nas doses que foram maternalmente tóxicas.

Os resultados do trabalho de Souza et al. (1994) mostraram que a fluoxetina tem efeitos múltiplos sobre o metabolismo energético da mitocôndria de figado de rato, sendo potencialmente tóxica em altas doses. Os efeitos parecem ser uma conseqüência da solubilização da droga e/ou metabólito na membrana interna da mitocôndria.

A ação genotóxica do prozac foi demonstrada por Breton, Vicentini e Mantovani (1999), ao tratarem células V79 (in vitro), com concentrações de 5mg, $2,5 \mathrm{mg}$ e $1,25 \mathrm{mg} / \mathrm{mL}$ de meio de cultura, por duas horas. Nesse experimento, o medicamento elevou o número de células com quebras cromossômicas. Os autores também demonstraram que a associação com as vitaminas $\mathrm{A}$ e $\mathrm{C}$ reduziu o número de células com alterações cromossômicas induzidas pelo prozac.

Vicentini et al. (2000), ao tratarem ratos com Prozac e com as vitaminas A e C, não encontraram mudanças nas frequências de células com alterações cromossômicas. Vicentini et al. (1999), utilizando o ensaio com células meristemáticas de raiz de Allium cepa, observaram que o Prozac reduziu significativamente o índice de proliferação celular após $24 \mathrm{~h}$ de tratamento, mas as associações com vitaminas $\mathrm{A}$ e C não modificaram esta resposta.

Sahu e Das (1994) eles avaliaram a redução do efeito clastogênico da clofazimina, que é uma droga antileprose, em células de medula óssea de camundongos, pelas vitaminas. Em vista da natureza não-genotóxica ( mesmo em doses relativamente altas) e da sua atividade altamente protetora, a vitamina $\mathrm{C}$, segundo os autores, e é preferível à vitamina A . Por isso, pode ser recomendada para ser administrada em conjunto com a clofazimina para minimizar ou anular o efeito genotóxico posterior. 
Esses dados, associados aos obtidos neste experimento, sugerem que o Prozac é um agente genotóxico em concentrações elevadas in vitro, mas não in vivo .Esse fato possivelmente ocorre devido a um efeito de metabolização. Já as vitaminas A e C apresentaram um bom efeito protetor in vitro, e isso sugere que possivelmente, em pacientes tratados com esses medicamentos, a utilização de vitaminas associadas possa ser uma alternativa segura, contudo, outras avaliações ainda devem ser realizadas.

\section{Referências}

BRETON, M. C.; VICENTINI, V. E. P.; MANTOVANI, M. S. Clastogenicidade do medicamento Prozac em cultura de células de mamíferos. Genetics And Molecular Biology, Ribeirao Preto, v.22, p.45, 1999.

BYRD, R. A.; MARKHAM, J. K. Developmental toxicology studies of fluoxetine hidrochloride administered orally to rats and rabbits. Fundamental And Applied Toxicology, Akron,v.22, n.4, p.511-518, 1994.

ODIN, A. P. Vitamins as antimutagens: Advantages and some possible mechanisms of antimutagenic action. Mutation Research., Amsterdam, v.386, p.39-67, 1997.

SACERDOTE, P.; BIACHI, M.; PANERAI, A. E. Chlorimipramine and Nortriptyline but not Fluoxetine and Fluvoxamine Inhibit Human Polymorphonuclear Cell Chemotaxis in vitro. General Pharmacology., Oxford, v.3, p.409-412, 1994.
SAHU, K.; DAS, R. K. Reduction of clastogenic effect of clofazimine, an antileprosy drug, by vitamin A and vitamin $\mathrm{C}$ in bone marrow cells of mice. Food And Chemical Toxicology, Oxford, v.32, n.10, p.911-915, 1994.

SINGH, N. P.; MCCOY, M. T.; TICE, R. R.; SCHNEIDER, E. L. A simple technique for quantitation of low levels of DNA damage in individual cells. Experimental Cell Research., New York, v.175, p.184-191, 1988.

SOUZA, M. E.; POLIZELLO, A. C.; UYEMURA, S. A.; CASTRO-SILVA, O.; CURTI, C. Effect of fluoxetine on rat liver mitochondria. Biochemical Pharmacology, New York, v.48, n.3, p.535-541, 1994.

VICENTINI, V. E. P.; SILVA, M. F.; MANTOVANI, M. S. Investigação da atividade mutagênica do prozac em vegetal, sem e com adição de vitaminas. Genetics and Molecular Biology, Ribeirão Preto, v.22, p.767, 1999.

VICENTINI, V. E. P.; MANTOVANI, M. S.; PERON, A. P.; MARIUCCI, R. G. Análise da ação mutagênica do antidepressivo prozac, em ratos tratados via gavagem. Genetics and Molecular Biology, Ribeirao Preto, v.23, p.703, 2000.

VORHEES, C. V.; ACUFF-SMITH, K. D.; SCHILLING, M. A.; FISHER, J. E.; MORAN, M. S.; BUELKE-SAM, J. A devlopmental neurotoxicity evaluation of the effects of prenatal exposure to fluoxetine in rats. Fundamental And Applied Toxicology, Akron., v.23, n.2, p.194-205, 1994.

WOOD, A. J. J. Drug therapy: fluoxetine. New England Journal of Medicine, Waltham, v.20, p.1354-1361, 1994. 